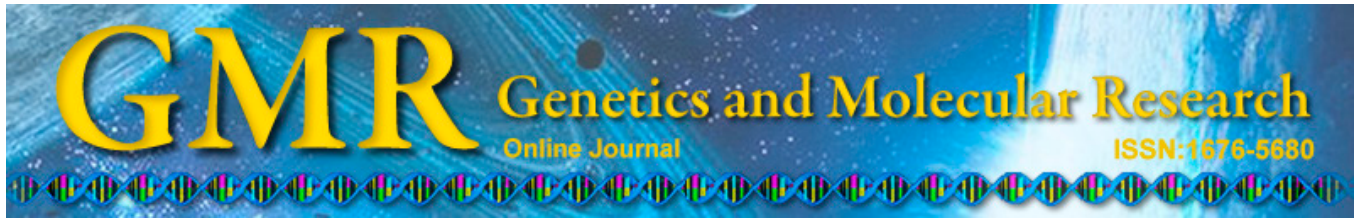

\title{
Genetic diversity and genetic structure of consecutive breeding generations of golden mandarin fish (Siniperca scherzeri Steindachner) using microsatellite markers
}

\author{
X.N. Luo ${ }^{1,2,3}$, M. Yang ${ }^{1,2}$, X.F. Liang ${ }^{1,2}$, K. Jin ${ }^{1,2}$, L.Y. Lv ${ }^{1,2}$, C.X. Tian ${ }^{1,2}$, \\ Y.C. Yuan ${ }^{1,2}$ and J. Sun ${ }^{1,2}$ \\ ${ }^{1}$ College of Fisheries, Key Lab of Freshwater Animal Breeding, \\ Ministry of Agriculture, Huazhong Agricultural University, Wuhan, Hubei, China \\ ${ }^{2}$ Hubei Collaborative Innovation Center for Freshwater Aquaculture, Wuhan, \\ Hubei, China \\ ${ }^{3}$ Freshwater Fisheries Science Institute of Liaoning Province, Liaoyang, China \\ Corresponding author: X.F. Liang \\ E-mail: xufang_liang@hotmail.com
}

Genet. Mol. Res. 14 (3): 11348-11355 (2015)

Received February 11, 2015

Accepted May 18, 2015

Published September 25, 2015

DOI http://dx.doi.org/10.4238/2015.September.25.1

\begin{abstract}
In this study, 12 polymorphic microsatellites were investigated to determine the genetic diversity and structure of 5 consecutive selected populations of golden mandarin fish (Siniperca scherzeri Steindachner). The total numbers of alleles, average heterozyosity, and average polymorphism information content showed that the genetic diversity of these breeding populations was decreasing. Additionally, pairwise fixation index $\mathrm{F}_{\mathrm{ST}}$ values among populations and Da values increased from $\mathrm{F} 1$ generation to subsequent generations $\left(\mathrm{F}_{\mathrm{ST}}\right.$ values from 0.0221-0.1408; Da values from 0.0608-0.1951). Analysis of molecular variance indicated that most genetic variations arise from individuals within populations (about 92.05\%), while variation among populations accounted for only $7.95 \%$. The allele frequency of the loci SC75-220
\end{abstract}


and SC101-222 bp changed regularly in the 5 breeding generations. Their frequencies were gradually increased and showed an enrichment trend, indicating that there may be genetic correlations between these 2 loci and breeding traits. Our study indicated that microsatellite markers are effective for assessing the genetic variability in the golden mandarin fish breeding program.

Key words: Aquaculture; Golden mandarin fish; Selective breeding; Microsatellite markers

\section{INTRODUCTION}

Golden mandarin fish (Siniperca scherzeri Steindachner), one of the most common freshwater fish in East Asia, is mainly distributed throughout East China, the Korean Peninsula, and Honghe River in Vietnam (Zhou et al., 1988). Because of its widespread, fast growth, and enjoyable taste, $S$. scherzeri has become an important economic aquaculture species in many East Asia countries. In China, S. scherzeri artificial breeding technology has advanced in recent years (Luo et al., 2014). Selective breeding programs are also underway, which has promoted the development of golden mandarin fish in the aquaculture industry. However, because of the absence of scientific management and advanced technology in S. scherzeri hatcheries, inbreeding and loss of genetic diversity are frequently detected in cultivated populations (Huang et al., 1999). Genetic diversity is important in species management, can provide information about population connectivity and adaptive potential, and allow insight into past events; thus, the relatively low level of genetic diversity may undermine environmental adaptive and resistance abilities of germplasm resources (Petersen et al., 2010). Thus, investigating the genetic diversity and structure of reared populations is necessary to maintain the fish health and sustain the $S$. scherzeri aquaculture industry.

In recent years, numerous studies on the propagation, farming, and nutrition of $S$. scherzeri have been reported (Zhao et al., 2009; Zhang et al., 2009; Tu et al., 2011), while few studies have focused on genetic variability and the population structure of reared populations. In this study, by using microsatellite markers, we estimated the genetic variation in 5 generations of a selected breeding line of golden mandarin fish, which has been established through collaboration between the Key Lab of Freshwater Animal Breeding, Ministry of Agriculture, and the Jing-Bo Hatchery in Dandong, Liaoning Province. The objective of this study was to demonstrate the effects of historical and ongoing domestication and cultivation on the $S$. scherzeri population genetic structure and diversity and to provide practical information regarding germplasm resources to increase the efficiency of $S$. scherzeri breeding programs.

\section{MATERIAL AND METHODS}

\section{Sampling and DNA extraction}

In 1998, a selective breeding program using mass selection for growth traits was established in Dandong city, Liaoning Province in China. A total of 600 original broodstock were gathered from the Yalu River. Next, 5 successive generations were constructed from 1998-2013, with a breeding program carried out every 3 years. Among each generation, 
individuals that were fast-growing, higher disease resistance, and standard size were maintained for the next breeding program. The fin chips of 36 samples randomly selected from each generation were sampled for genetic analysis and stored in ethanol. Total genomic DNA was extracted from fin clips using the TIANamp Genomic DNA Kit (Tiangen Biotech, Beijing, China) following the manufacturer instructions. The DNA was adjusted to $100 \mathrm{ng} /$ $\mu \mathrm{L}$ and stored at $-20^{\circ} \mathrm{C}$.

\section{Microsatellite analysis}

Twelve primer pairs for the S. scherzeri microsatellite markers, SC01, SC75, SC80, SC90, SC101, SC175, Sin155, SO352, SS206, SS55, SS224, and SS265 (Qu et al., 2012; Huang et al., 2013), were polymerase chain reaction (PCR)-amplified in a $12.5-\mu \mathrm{L}$ reaction volume containing $50 \mathrm{ng}$ template DNA, $0.25 \mu \mathrm{M}$ of each primer, $0.25 \mathrm{mM}$ of each dNTP, $2.5 \mu \mathrm{L} 10 \mathrm{X}$ loading buffer, and $0.125 \mathrm{U}$ rTaq polymerase (TaKaRa, Shiga, Japan). Thermal cycling conditions for each locus were: $3 \mathrm{~min}$ at $94^{\circ} \mathrm{C}$, followed by 30 cycles of $94^{\circ} \mathrm{C}$ for $30 \mathrm{~s}$, annealing temperature (Table 1) for $45 \mathrm{~s}$, and $72^{\circ} \mathrm{C}$ for $30 \mathrm{~s}$, with a final extension of $72^{\circ} \mathrm{C}$ for $10 \mathrm{~min}$. Primers were synthesized by Sangon Biotech (Shanghai, China), and forward primers were labeled with a fluorescent dye (FAM, HEX, and ROX) at the $5^{\prime}$ end. PCR amplification carried out using an Eppendorf Mastercycler pro 384 PCR thermocyclers (Eppendorf, Hamburg, Germany). PCR products were separated using an automatic capillary sequencer (ABI 3130 Genetic Analyzer, Applied Biosystems, Foster City, CA, USA) at Sangon Biotech (Shanghai, China). Fragment sizes were determined using the GeneMapper $^{\circledR}$ software version 4.0 (Applied Biosystems) by comparison against a GenScanTM 500 ROXTM (Applied Biosystems) internal size standard.

\begin{tabular}{|c|c|c|c|c|}
\hline Primer code & Accession No. & Repeat motif & Primer sequence $\left(5^{\prime}-3^{\prime}\right)$ & $\operatorname{Tm}\left({ }^{\circ} \mathrm{C}\right)$ \\
\hline $\mathrm{SC} 01$ & JQ686834 & $(\mathrm{TCA})_{12}$ & $\begin{array}{l}\text { F: TTTTAAAGACGGGGCAGCGG } \\
\text { R: ACCAACGTTTGGCGTAAAGC }\end{array}$ & 60 \\
\hline SC75 & JQ804734 & $(\mathrm{CA})_{12}$ & $\begin{array}{l}\text { F: CCGCAGAACCAGCAATTCAC } \\
\text { R: AGCAAGACCAGGAAACCAGAC }\end{array}$ & 57 \\
\hline SC 80 & JQ804737 & $(\mathrm{TCA})_{9}$ & $\begin{array}{l}\text { F: ATCAGCTCAACCCCTCTGCAT } \\
\text { R: GCATGGATGCCAGCGTGAG }\end{array}$ & 60 \\
\hline SC90 & JQ804746 & $(\mathrm{TG})_{16}$ & $\begin{array}{l}\text { F: GCTTTATTTAGTTACCCTGTG } \\
\text { R: CAGCCAACACTCTTCACAT }\end{array}$ & 53 \\
\hline SC101 & JQ804757 & $(\mathrm{AC})_{15}$ & $\begin{array}{l}\text { F: TTCTGTTCAAAAGTACAGTAACCT } \\
\text { R: AGGCCCTGATAAGAAACACAGA }\end{array}$ & 55 \\
\hline SC175 & JQ804828 & $(\mathrm{TGA})_{8}$ & $\begin{array}{l}\text { F: TACATGCACACCAGTACGGC } \\
\text { R: CACCCCGTTAAGTCCACGTC }\end{array}$ & 57 \\
\hline $\operatorname{Sin} 155$ & JQ804809 & $(\mathrm{AC})_{13}$ & $\begin{array}{l}\text { F: GAATGGTGTGTTGCACAGCG } \\
\text { R: CATTCTAGCATGTGCGAGGC }\end{array}$ & 57 \\
\hline $\mathrm{SO} 352$ & JX443458 & $(\mathrm{CA})_{10}$ & $\begin{array}{l}\text { F: CGAGTGTTTGATTTCTTCCTC } \\
\text { R: GTGTAAATACTGAAGGCTCG }\end{array}$ & 60 \\
\hline SS206 & JX294974 & $(\mathrm{TCA})_{8}$ & $\begin{array}{l}\text { F: CGAACCGTCTCACTTCGTCC } \\
\text { R: AAACAAACTGGCGTGTGGGT }\end{array}$ & 57 \\
\hline SS55 & JQ686886 & $(\mathrm{TG})_{19}$ & $\begin{array}{l}\text { F: GGTGATGTGAGAAAATCCGAGG } \\
\text { R: GTATCCTCACTGAAAAACAGGAC }\end{array}$ & 60 \\
\hline SS224 & JX294981 & $(\mathrm{TCC})_{8}$ & $\begin{array}{l}\text { F: TTGTTCCCGGGTGTCCCTTA } \\
\text { R: TTGTCTCGAGCTGTTGCGG }\end{array}$ & 57 \\
\hline SS265 & JX294992 & $(\mathrm{AC})_{11}$ & $\begin{array}{l}\text { F: GCGCCTATGTTGGCCAGTAA } \\
\text { R: GGTGTCATGATCTCCACGGC }\end{array}$ & 57 \\
\hline
\end{tabular}




\section{Data analysis}

MICRO-CHECKER version 2.2.3 (Van Oosterhout et al., 2004) was used to identify possible genotyping errors within each locus. The mean number of alleles $\left(N_{\mathrm{A}}\right)$ and the observed $\left(H_{\mathrm{O}}\right)$ and expected $\left(H_{\mathrm{E}}\right)$ heterozygosities were determined using FSTAT version 2.9.3 (Goudet, 2001). GENEPOP version 4.0 (Raymond and Rousset, 1995) was used to test genotypic distributions for conformance to Hardy-Weinberg equilibrium (HWE) and the loci for genotypic linkage disequilibrium. Locus conformance to HWE was assessed using exact tests (with default Markov chain parameters); Wright's fixation index $\left(\mathrm{F}_{\mathrm{IS}}\right.$; an inbreeding coefficient) for each locus-site combination was used to determine the nature of the departures (where $\mathrm{F}_{\mathrm{IS}}<0$ indicated heterozygote excess and $\mathrm{F}_{\mathrm{IS}}>0$ indicated heterozygote deficits). Significant levels were adjusted for multiple comparisons using sequential Bonferroni's correction (Rice, 1989). Temporal and regional comparisons of genetic heterogeneity among regions were conducted using analysis of molecular variance implemented in Arlequin 3.5 (Excoffier and Lischer, 2010). An exact test of population differentiation of pairwise weighted mean $\mathrm{F}_{\mathrm{ST}}$ (Weir and Cockerham, 1984) was performed using Arlequin 3.5. A neighborhood joining dendrogram was constructed based on Nei's distance (Da) matrix by carrying out 1000 bootstrap replications using the Populations 1.2.30 program (http://bioinformatics.org/tryphon/population) to determine the genetic relationships among populations.

\section{RESULTS}

\section{Changes in genetic diversity over generations}

In this study, the 12 microsatellite loci totally detected 57 alleles in the 5 generations, indicating that the number of alleles in each loci ranged from 3-7. Table 2 shows data for every generation, including $N_{\mathrm{A}}$, average number of effective alleles $\left(N_{\mathrm{E}}\right), \mathrm{F}_{\mathrm{IS}}$, average $H_{\mathrm{O}}$, average $H_{\mathrm{E}}$, and average polymorphic information content. We found that the F1 and F2 generations showed the highest and very similar levels of genetic diversity. Beginning in the F2 generation, as the selective breeding generation increased, the genetic diversity level of generation populations gradually decreased, while the value of $\mathrm{F}_{\mathrm{IS}}$ gradually increased, reaching a maximum value in the $\mathrm{F} 4$ generation $(0.138)$. For example, genetic diversity of $N_{\mathrm{A}}$ ranged from $4.75-3.92, H_{\mathrm{E}}$ from $0.644-0.426, H_{\mathrm{O}}$ from $0.724-0.359$, and polymorphic information content from $0.585-0.385$.

\section{Table 2. Average genetic variability of the 12 microsatellite loci in each selective breeding generation.}

\begin{tabular}{|c|c|c|c|c|c|c|}
\hline & $\mathrm{F} 1$ & $\mathrm{~F} 2$ & F3 & F4 & F5 & Mean \\
\hline Simple size & 42 & 43 & 40 & 44 & 43 & 212 \\
\hline Total $N_{\mathrm{A}}$ & 57 & 57 & 51 & 49 & 47 & 57 \\
\hline Mean $N_{A}$ & 4.75 & 4.75 & 4.25 & 4.08 & 3.92 & 4.35 \\
\hline$N_{\mathrm{E}} \quad$ A & 3.20 & 2.96 & 2.67 & 2.37 & 1.88 & 2.62 \\
\hline $\mathrm{F}_{\mathrm{IS}}^{\mathrm{E}}$ & -0.147 & 0.001 & 0.112 & 0.138 & 0.115 & 0.044 \\
\hline$H_{\mathrm{E}}$ & 0.644 & 0.635 & 0.597 & 0.516 & 0.426 & 0.564 \\
\hline$H_{0}$ & 0.724 & 0.620 & 0.525 & 0.430 & 0.359 & 0.532 \\
\hline $\begin{array}{l}0 \\
\text { PIC }\end{array}$ & 0.585 & 0.583 & 0.535 & 0.466 & 0.385 & 0.511 \\
\hline
\end{tabular}


Observation of allele frequencies of microsatellite loci for 5 generations showed that the allele frequencies of most loci exhibited random variations in the breeding process (i.e., fluctuation in allele frequencies in different generations). There were some exceptions, such as the allele of the loci SC75-220 and SC101-222 bp; their gene frequencies were increased with breeding (Table 3). Additionally, many low frequency alleles disappeared during the breeding process.

\begin{tabular}{|c|c|c|c|c|c|}
\hline & $\mathrm{F} 1$ & F2 & F3 & F4 & F5 \\
\hline \multicolumn{6}{|l|}{ Y75 } \\
\hline 220 & 0.55 & 0.53 & 0.59 & 0.76 & 0.73 \\
\hline 224 & 0.08 & 0.08 & 0.16 & 0.07 & 0.08 \\
\hline 226 & 0.06 & 0.07 & 0 & 0 & 0 \\
\hline 228 & 0.17 & 0.14 & 0.13 & 0.08 & 0.09 \\
\hline 232 & 0.07 & 0.13 & 0.09 & 0.07 & 0.07 \\
\hline 236 & 0.07 & 0.05 & 0.04 & 0.02 & 0.02 \\
\hline \multicolumn{6}{|l|}{ Y101 } \\
\hline 213 & 0.11 & 0.12 & 0.29 & 0.03 & 0 \\
\hline 222 & 0.36 & 0.52 & 0.66 & 0.93 & 0.95 \\
\hline 226 & 0.15 & 0.03 & 0 & 0 & 0 \\
\hline 230 & 0.11 & 0.06 & 0 & 0 & 0 \\
\hline 232 & 0.21 & 0.22 & 0.05 & 0.03 & 0.05 \\
\hline 236 & 0.06 & 0.05 & 0 & 0 & 0 \\
\hline
\end{tabular}

Pairwise genetic differentiation among populations $\left(\mathrm{F}_{\mathrm{ST}}\right)$ and genetic distance $(\mathrm{Da})$ have high consistency (Table 4). $\mathrm{F}_{\mathrm{ST}}$ values among populations and Da values increased in the $\mathrm{F} 1$ generation and subsequent generations $\left(\mathrm{F}_{\text {Ст }}\right.$ values from 0.0221-0.1408; Da values from 0.0608-0.1951), and pairwise genetic differentiation and genetic distance between adjacent generations were also increased over successive selection generations $\left(\mathrm{F}_{\mathrm{ST}}\right.$ values from 0.0221-0.1288; Da values from 0.0608-0.1481). The largest pairwise genetic differentiation and genetic distance were detected from the F2-F5 generations ( $\mathrm{F}_{\mathrm{ST}}$ values 0.1448 ; Da values 0.2013 ), while the lowest pairwise genetic differentiation and genetic distance were detected between the F1 and F2 generations ( $\mathrm{F}_{\mathrm{ST}}$ values 0.0221; Da values 0.0608). Genetic differentiation ( $\mathrm{F}_{\mathrm{ST}}$ values) among populations was significant. The analysis of molecular variance indicated that most genetic variations arise from individuals within populations (approximately $92.05 \%$ ), while variation among populations accounted for only $7.95 \%$ (Table 5). As shown on the clustering map, which was constructed by Nei's genetic distance using the unweighted pair group method with arithmetic mean (UPGMA) model, the F5 generations was clustered in 1 branch, while other populations were gathered in another large branch (Figure 1).

Table 4. Pairwise genetic differentiation $\mathrm{F}_{\mathrm{ST}}$ among generations (bottom left) and genetic distance Da (upper right).

\begin{tabular}{lccccc}
\hline & F1 & F2 & F3 & F4 & F5 \\
\hline F1 & - & 0.0608 & 0.0614 & 0.1050 & 0.1951 \\
F2 & $0.0221^{*}$ & - & 0.0849 & 0.1171 & 0.2013 \\
F3 & $0.0250^{*}$ & $0.0431^{*}$ & - & 0.0903 & 0.1285 \\
F4 & $0.0648^{*}$ & $0.0721^{*}$ & $0.0540^{*}$ & - & 0.1481 \\
F5 & $0.1408^{*}$ & $0.1448^{*}$ & $0.1053^{*}$ & $0.1288^{*}$ & - \\
\hline
\end{tabular}

$* \mathrm{P}<0.05$. 
Table 5. Analysis of molecular variance (AMOVA) of 5 generations.

\begin{tabular}{lrccr}
\hline Source of variation & d.f. & Sum of squares & Variance components & Percentage of variation \\
\hline Among populations & 4 & 112.401 & 0.29165 & 7.95 \\
Within populations & 419 & 1414.099 & 3.37494 & 92.05 \\
Total & 423 & 1526.5 & 3.66658 & \\
\hline
\end{tabular}

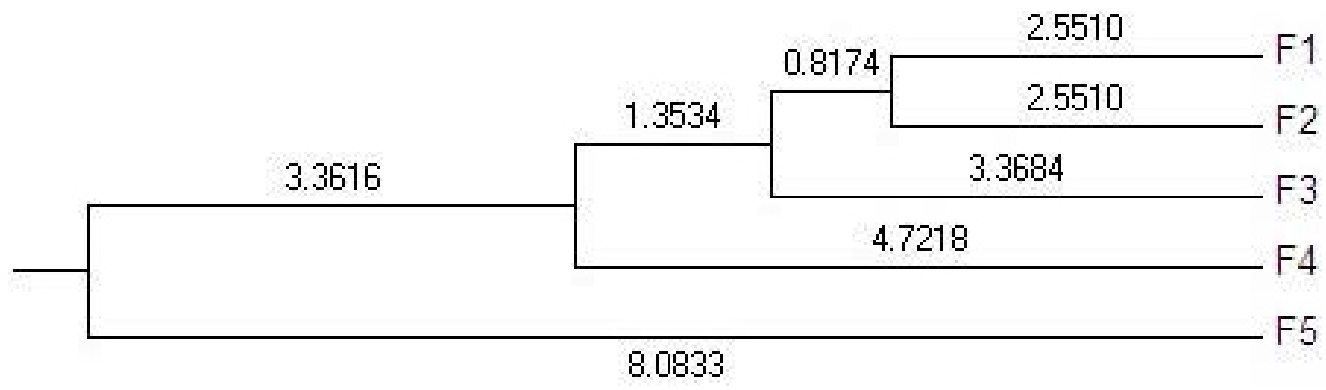

Figure 1. Nei's distance tree using the UPGMA model of 5 generations of populations (the numbers in figure represent branch length).

\section{DISCUSSION}

\section{Genetic diversity and allele frequencies of populations}

Various studies have used microsatellite markers to conduct genetic monitoring in selective breeding lines, such as Pseudosciaena crocea (Hao et al., 2010) and Ruditapes philippinarum (Yu et al., 2011). However, there have been no such reports for S. scherzei. In this study, selected microsatellite loci showed moderate levels of genetic diversity in the F1 generation populations $\left(N_{\mathrm{A}}=4.75 ; H_{\mathrm{E}}=0.644 ; H_{\mathrm{O}}=0.724\right)$, which was similar to the values reported by Cao et al. (2013). Additionally, over 5 breeding generations, the $N_{\mathrm{A}}, H_{\mathrm{O}}$, and $H_{\mathrm{E}}$ of $S$. scherzeri were reduced over generations. This result is consistent with that obtained in Japanese flounder (Sekino et al., 2002) and oysters (English et al., 2001). The findings above indicate that artificial directional selection allow the population genotype to become further pure, leading to a reduction in the population genetic diversity.

$\mathrm{F}_{\mathrm{IS}}$ reflects the degree of inbreeding in a population. Its value ranges from -1 to 1 , and a higher value indicates more prevalent inbreeding within a population (Weir and Cockerham, 1984). In this study, we found that $F_{\text {IS }}$ values gradually increased over successive generations, indicating inbreeding in the populations was increasing. Additionally, heterozygous deletion in the population also increased. These findings agree with those of various other reports of aquaculture species (Addison and Hart, 2004; Valles-Jimenez et al., 2004; Sato et al., 2005). Allele frequencies are also very important, and fluctuations in their values indicate changes in a population. Changes in allele frequencies reflect variations in the genetic structure of a population (Guan et al., 2013). According to our analysis of allele frequencies, the loci SC75220 and SC101-222 bp showed regular changes in frequency. Their frequencies gradually increased, showing an enrichment trend, indicating that genetic correlations may exist between these 2 loci and breeding traits. However, to confirm this relationship, further association 
analysis studies between traits are necessary.

\section{Genetic structure of populations}

Pairwise $\mathrm{F}_{\mathrm{ST}}$ values among the 5 generations were all significant, and as selection continued, genetic differentiation and genetic distances between the F1 generation and successive generations increased ( $\mathrm{F}_{\mathrm{ST}}$ values from 0.0221-0.1408; Da values from 0.0608-0.1951). This result indicates that artificial selection had a very significant impact on the genetic structure of the breeding populations. We also found that the genetic differentiation index and genetic distance between adjacent generations increased over selection generation $\left(\mathrm{F}_{\mathrm{ST}}\right.$ values from 0.0221-0.1288; Da values from 0.0608-0.1481), which was also very clear on the UPGMA tree. The map of the UPGMA tree was based on Nei's genetic distance (Yeh, 1997). This result, which is displayed in UPGMA tree, disagrees with the results for other aquatic species. This may be because the generation populations of breeding had not fully adapted to the existing selection pressure and environment, and thus the population genetic structure had not yet stabilized. Additionally, the populations may require further breeding activities to reach a stable genetic structure in order to ensure the genetic stability of breeding traits.

Artificial selection causes genes in breeding populations to become homozygous; the affected genes are typically associated with a target trait. This is conducive to the stability of breeding traits and the formation of species characteristics, but also leads to a loss in population polymorphisms. Hence, in breeding processes, homozygosity fixes the frequencies of genes associated with a target trait, while maintaining polymorphisms in gene loci to the extent possible. Whether this method can ensure that populations have both higher flexibility and further potential improvement requires further investigation.

\section{ACKNOWLEDGMENTS}

Research supported by the Key Projects in the National Science \& Technology Pillar Program during the Twelfth Five-year Plan Period (\#2012BAD25B00), the National Natural Science Foundation of China (\#31272641, \#31172420), the National Basic Research Program of China (\#2009CB118702), the Fundamental Research Funds for the Central Universities (\#2011PY030), the Huazhong Agricultural University Scientific \& Technological Self-innovation Foundation (\#2012SC24), and the Fundamental Research Funds for the Central Universities (\#2013PY072).

\section{REFERENCES}

Addison JA and Hart MW (2004). Analysis of population genetic structure of the green sea urchin (Strongylocentrotus droebachiensis) using microsatellites. Mar. Biol. 144: 243-251.

Cao L, Liang XF, Tang W and Zhao J (2013). Phylogeography of Coreoperca whiteheadi (Perciformes: Coreoperca) in China based on mitochondrial and nuclear gene sequences. Biochem. Syst. Ecol. 50: 223-231.

English LJ, Nell JA, Maguire GB and Ward RD (2001). Allozyme variation in three generations of selection for whole weight in Sydney rock oysters (Saccostrea glomerata). Aquaculture 193: 213-225.

Excoffier L and Lischer HE (2010). Arlequin suite ver 3.5: a new series of programs to perform population genetics analyses under Linux and Windows. Mol. Ecol. Resour. 10: 564-567.

Goudet J (2001). FSTAT, a program to estimate and test gene diversities and fixation indices (version 2.9. 3). Available at [http://www.unil.ch/izea/softwares/fstat.html]. Accessed October 15, 2013.

Guan YY, Liu WG and He MX (2013). Genetic variation during four generations of selective breeding in the pearl oyster 
Pinctada fucata. J. Fish. China 4: 764-770.

Hao GT, Liu XD, Wang ZY, Cai MY, et al. (2010). Genetic structure and genetic diversity analysis of four consecutive breeding generations of large yellow croaker (Pseudosciaena crocea) using microsatellite markers. J. Fish. China 34: 500-507.

Huang W, Liang XF, Qu CM, Zhao C, et al. (2013). Isolation and characterization of 31 polymorphic microsatellite markers in Siniperca obscura Nichols. Conservation Genet. Resour. 5: 153-156.

Huang ZJ, He JG, Wen SP and Zeng K (1999). The isolation and preliminary identification of pathogenic bacteria from the diseased Mandarin fish. Microbiol. China 26: 241-246.

Luo XN, Liang XF, Zhou Yi, Yuan YC, et al. (2014). A review of research progress of aquaculture biology in spotted Mandarin fish Siniperca scherzeri. Fisheries Sci. 33: 56-62.

Petersen JL, Ibarra AM and May B (2010). Nuclear and mtDNA lineage diversity in wild and cultured Pacific lion-paw scallop, Nodipecten subnodosus (Baja California Peninsula, Mexico). Mar. Biol. 157: 2751-2767.

Qu C, Liang XF, Huang W and Cao L (2012). Isolation and characterization of 46 novel polymorphic EST-simple sequence repeats (SSR) markers in two sinipercine fishes (Siniperca) and cross-species amplification. Int. J. Mol. Sci. 13: 9534-9544.

Raymond M and Rousset F (1995). GENEPOP (version 1.2): population genetics software for exact tests and ecumenicism. J. Hered. 86: 248-249.

Rice WR (1989). Analyzing tables of statistical tests. Evolution 43: 223-225.

Sato M, Kawamata K, Zaslavskaya N, Nakamura A, et al. (2005). Development of microsatellite markers for Japanese scallop (Mizuhopecten yessoensis) and their application to a population genetic study. Mar. Biotechnol. 7: 713-728.

Sekino M, Hara M and Taniguchi N (2002). Loss of microsatellite and mitochondrial DNA variation in hatchery strains of Japanese flounder (Paralichthys olivaceus). Aquaculture 213: 101-122.

Tu GJ, Wu XB, Yan P and Lu JQ (2011). The research on artificial propagation and larval rearing of Siniperca scherzeri Steindachner in Changiiang River. J. Hydroecol. 3: 137-191.

Valles-Jimenez R, Cruz P and Perez-Enriquez R (2004). Population genetic structure of Pacific white shrimp (Litopenaeus vannamei) from Mexico to Panama: microsatellite DNA variation. Mar. Biotechnol. 6: 475-484.

Van Oosterhout C, Hutchinson WF, Wills DPM and Shipley P (2004). Micro-Checker: software for identifying and correcting genotyping errors in microsatellite data. Mol. Ecol. Notes 4: 535-538.

Weir BS and Cockerham CC (1984). Estimating F-statistics for the analysis of population structure. Evolution 38: 1358-1370.

Yeh F (1997). Population genetic analysis of codominant and dominant markers and quantitative traits. Belg. J. Bot. 129: 157.

Yu ZF, Yan XW, Yang F, Wang JH, et al. (2011). Genetic diversity of different generations of the Dalian population of Manila clam Ruditapes philippinarum through selective breeding. Acta Ecol. Sin. 31: 4199-4206.

Zhang L, Wang Y, Hu M, Fan Q, et al. (2009). Effects of the timing of initial feeding on growth and survival of spotted mandarin fish Siniperca scherzeri larvae. J. Fish. Biol. 75: 1158-1172.

Zhao XL, Xia DM, Luo XN, Yang PM, et al. (2009). Growth characteristics and culture pattern of Siniperca scherzeri Steindachner cultured in cage. Chin. J. Fish. 2: 009.

Zhou CW, Yang Q and Cai DL (1988). On the classification and distribution of the Sinipercinae fishes (family Serranidae). Zool. Res. 9: 113-125. 